\title{
Multi-Layer Perceptron Neural Network for Air Wave Estimation in Marine Control Source Electromagnetic Data
}

\author{
Muhammad Abdulkarim, Afza Shafie, Noorhana Yahya, Wan Fatimah Wan Ahmad and Radzuan \\ Razali
}

\begin{abstract}
Marine Control Source Electro-Magnetic (MCSEM) survey is a technique for remote identification of subsea floor structures of the earth's interior using Electro-Magnetic (EM) signals. Air wave signal is major problem associated with the data recorded by this technique in shallow water environment. The air wave signals are parts of the EM signals that propagate from EM source via the atmosphere and induced along air/sea surface. These air wave signals has the ability to limit and mask the electromagnetic response of a subsurface resistive body so that signals from subsurface, possibly containing valuable information about a resistive hydrocarbon reservoir is hardly distinguishable. This paper presents the application of a feed forward multi-layer perceptron neural networks model for estimation of air waves in MCSEM survey data based on offset and sea water depth values. The proposed model has 3 hidden layers with sigmoid activation function, an output layer with purelin transfer function and Levenberg-Marquardt (trainlm) as the training function. Simulated airwave data for ten sea water depths from $1000 \mathrm{~m}$ to $100 \mathrm{~m}$ at interval of $100 \mathrm{~m}$ were used as the training data. Coefficient of multiple determination and Mean Square Error (MSE) obtained from the multi-layer perceptron model and the estimation with multiple linear regression model are compared. Preliminary results demonstrate that multi-layer perceptron neural networks are a viable technique for the estimation of air waves in MCSEM data.
\end{abstract}

Manuscript submitted February 29, 2012. This work was supported in part by the Universiti Teknologi PETRONAS for the financial support in the form of a research grant: Fundamental and Research Grant Scheme, and also simulation facilities including Multi-Physics simulation software.

Muhammad Abdulkarim is with the Department of Computer \& Information Sciences, Universiti Teknologi PETRONAS, Bandar Seri Iskandar, 31750 Tronoh, Perak, Malaysia phone: +601-777-60723; fax: +605 365 5905; (e-mail: muhammad_g01387@utp.edu.my).

Afza Shafie is with the Department of Fundamental \& Applied Sciences, Universiti Teknologi PETRONAS, Bandar Seri Iskandar, 31750 Tronoh, Perak, Malaysia (e-mail: afza @ petronas.com.my).

Noorhana Binti Yahya is with the Department of Fundamental \& Applied Sciences, Universiti Teknologi PETRONAS, Bandar Seri Iskandar, 31750 Tronoh, Perak, Malaysia (e-mail: noorhana_yahya@petronas.com.my).

Wan Fatimah Wan Ahmad is with the Department of Computer \& Information Sciences, Universiti Teknologi PETRONAS, Bandar Seri Iskandar, $31750 \quad$ Tronoh, Perak, Malaysia (e-mail: fatimhd@petronas.com.my).

Radzuan Razali is with the Department of Fundamental \& Applied Sciences, Universiti Teknologi PETRONAS, Bandar Seri Iskandar, 31750 Tronoh, Perak, Malaysia (e-mail: radzuan_razali@petronas.com.my).
Index Terms-Air waves; Coefficient of Multiple Determination; Control Source Electro-Magnetic; Mean Square Error; Multi-Layer Perceptron; Multiple Linear Regression

\section{INTRODUCTION}

A new application of the Controlled Source ElectroMagnetic method (CSEM) for offshore oil exploration called Sea Bed Logging (SBL) has recently become an important complementary tool to seismic exploration technique to evaluate possible hydrocarbon-bearing prospects. This technique has the ability to provide information about resistivity variations beneath the seafloor which is crucial in off-shore hydrocarbon exploration. Traditionally, measurements of electrical resistivity beneath sub-seafloor in the oil and gas industry were obtained almost exclusively by wire-line logging of wells [1, 2]. CSEM technique has provided encouraging results over the past few years [3, 4].

Theoretically, CSEM surveys is based on the knowledge that the propagation of an electromagnetic (EM) fields induced in a conductive subsurface is mainly affected by spatial distribution of resistivity [5]. The basis of the approach is the use of a mobile horizontal electric dipole (source) which is being towed approximately $30-40 \mathrm{~m}$ above the seabed, and an array of electromagnetic receivers equipped with electric and magnetic sensors on the seabed to record both the amplitude and the phase of the received signals. The transmitting dipole emits an ultra-low frequency $(\sim 0.1-5 \mathrm{~Hz})$ electromagnetic signal both into the seawater column and downward into the subsurface as shown in Fig. 1.

The airwave component is predominantly generated by the EM signal component that diffuses vertically upward then propagates as a "wave" through the air at the speed of light with no attenuation before diffusing back down vertically through the water layer to the sea bottom, where it is picked up by the EM receivers [6].

The contribution of the airwave to the marine CSEM response is investigated by [7] in a numerical model study for marine CSEM exploration using an HED source. They point out that the effect of the airwave component is important at large offsets, at low frequencies, or in relatively shallow water depths. However, they do not give any method to compute the airwave effect other than by numerical modeling. Numerical 
calculations for a 1D model using the Hankel transform as developed by [8] yield a fast algorithm, but the algorithm does not give physical insight as to how the airwave component builds up and behaves in the water layer.

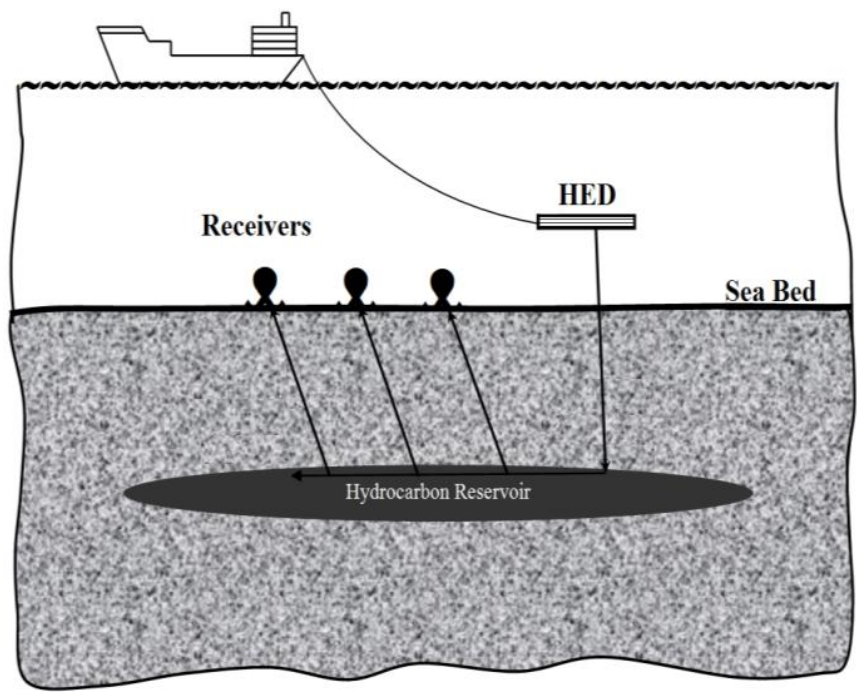

Fig. 1. Schematic Diagram of CSEM Survey.

Study by [6] has shown the effect of seawater depth would be important at large source-receiver separations, low frequencies, or in relatively shallow water. It was also pointed out how the airwave component in principle can be suppressed by a modeling-and-subtraction approach. The effect can be incorporated into the theory if both water depth and source location are accurately determined [8].

Features of the effect of the air wave on the amplitude and phase was described by [2] and reported that the range at which the air wave dominates the response, and information on seabed resistivity is lost, increases with decreasing frequency and water depth.

The petroleum industry has also found significant use of neural networks to process seismic and potential-field data for oil explorations $[9,10]$. The neural networks has been used in works such as interpreting well logs, processing of EM sounding data, recognizing seismic waveforms, function approximation, electromagnetic, magneto telluric and seismic inversion purposes and for many other problems $[11,12)]$.

Artificial Neural Network (ANN) is a method of computation and information processing that emulates biological neural system. The method is good at fitting functions and recognizing patterns. In fact, there is proof that a fairly simple neural network can fit any practical function [10]. The applications of artificial neural network techniques have in recent times found wide potential use for geophysical data processing, e.g. prediction, inversion, feature classification and data compression [14 - 18].

The ANN technique was applied to the control source electromagnetic data processing in a scaled model marine environment as well as the classification of MCSEM data by $[19,20]$ with radial basis function neural network, and the results indicated superior accuracy, sensitivity and specificity in classifying the MCSEM data.
The ANN technique has the advantage of firstly, ability to be used as an arbitrary function approximation mechanism which 'learns' from observed data. Secondly, it has the advantage of not being constraint to satisfy any parametric assumptions. These are two main reasons that forms the authors motivation in this study to apply this technique for the estimation of air waves in MCSEM data.

The objective of this paper is to study the feasibility of using a Multi-Layer Perceptron (MLP) neural network model for the estimation of air wave in MCSEM data. Synthetic data from ten different sea water depths (SWD) of CSEM set-ups were used. The SWD is from $1000 \mathrm{~m}$ to $100 \mathrm{~m}$ at an interval of $100 \mathrm{~m}$. The paper is organized as follows; Section II describes the architecture of the MLP model, followed by the simulation set-ups in Section III. The results and discussion will be given in Section IV and the conclusions in Section V.

\section{ARChitecture OF MUlti-LAYER PERCEPTRON}

In this study, a feed forward back propagation neural network was used. The neural network is structured with two neurons in the input layer, five neurons in the hidden layer and one neuron for the output layer shown in Fig. 2.

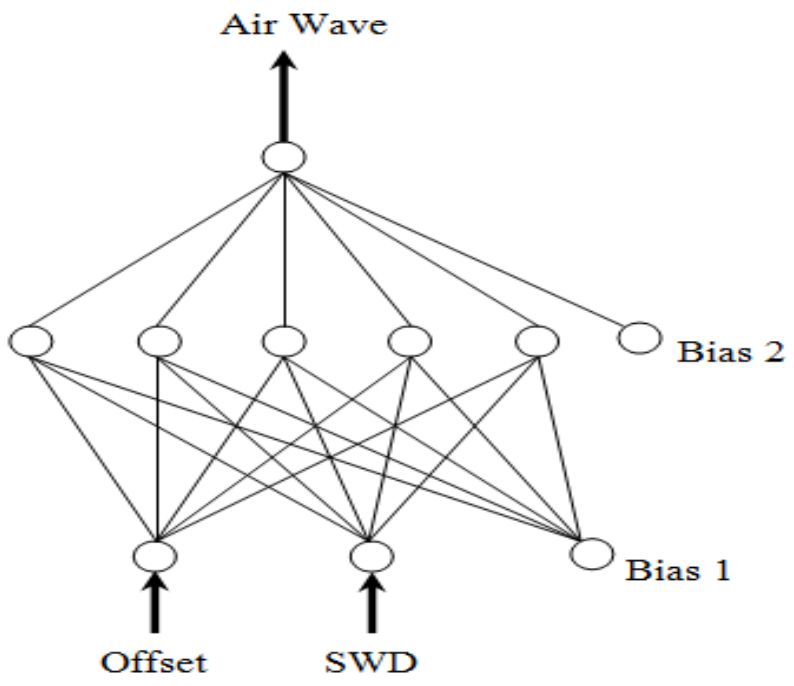

Fig. 2. Architecture of Multi-Layer Perceptron Neural Network.

The activation function, logsig, is used in the hidden layer mentioned in equation (1) and purelin function is used in output layer mentioned in equation (2).

$$
\begin{gathered}
f(x)=\frac{1}{1+e^{-x}} \\
f(x)=x+\text { Bias }
\end{gathered}
$$

The algorithm for the minimization of the error function is carried out using a gradient descent technique. The necessary corrections to the weights of the network for each moment $t$ are obtained by calculating the partial derivative of the error function in relation to each weight $\mathrm{w}_{\mathrm{ij}}$. A gradient vector representing the steepest increasing direction in the weight space is thus obtained. The resulting weight update is then 
computed [17]. The algorithm for the gradient descent is presented.

\section{Gradient Descent Algorithm}

Gradient descent algorithm also known as steepest descent is a process of making changes to weights and biases in order to find the global minimum of error for a network. The changes are proportional to the derivatives of network error with respect to those weights and biases. This is done to minimize network error. The combine error measure, $\mathrm{E}$, for $n$ number of observation is defined as:

$$
\mathrm{E}=\sum_{n} \mathrm{E}^{n}
$$

The error for the points $n$, and every individual error is defined as:

$$
\mathrm{E}^{n}=\frac{1}{2} \sum_{o}\left(t_{o}^{n}-y_{o}^{n}\right)^{2}
$$

Where $\mathrm{t}_{o}$ is the target or desired output, $\mathrm{y}_{o}$ is the actual output, $o$ is the number of the different output unit that is existing in our neural network system and $n$ is the number of point over which we are observing.

The gradient is therefore given by:

$$
\begin{aligned}
G & =\frac{\partial \mathrm{E}}{\partial w_{i j}} \\
& =\frac{\partial}{\partial w_{i j}} \sum_{n} \mathrm{E}^{n}=\sum_{n} \frac{\partial \mathrm{E}^{n}}{\partial w_{i j}}
\end{aligned}
$$

Where $w_{i j}$ is the synaptic interconnection weight.

Applying the chain rule of differentiation

$$
\frac{\partial \mathrm{E}}{\partial w_{o i}}=\frac{\partial \mathrm{E}}{\partial y_{o}} \cdot \frac{\partial y_{o}}{\partial w_{o i}}
$$

Where $y_{o}=\sum_{j} w_{o j} x_{j}$

It implies that $\frac{\partial y_{o}}{\partial w_{o j}}=\frac{\partial}{\partial w_{o j}} \sum_{j} w_{o j} x_{j}=x_{j}$

From equation (2)

$$
\frac{\partial \mathrm{E}}{\partial y_{o}}=-\left(t_{o}-y_{o}\right)
$$

Therefore the gradient is:

$$
G=\frac{\partial \mathrm{E}}{\partial w_{o i}}=-\left(t_{o}-y_{o}\right) x_{i}
$$

Equation (6) is the correction that is applied to the weight.

\section{SIMULATION SET-UP}

Computer Simulation Technology (CST) software was used to simulate the sea bed environment. The area simulated is $25 \mathrm{Km}$. The transmitter is modeled as a short 1250A AC line current segment of length $270 \mathrm{~m}$ of frequency $0.125 \mathrm{~Hz}$ is located $35 \mathrm{~m}$ above the sea bed. At the external spherical boundaries, a scattering boundary condition absorbs outgoing spherical waves. The Maxwell's electromagnetic field wave equation in vacuum in the absence of electric or magnetic sources is solved for the electric field vector $\mathrm{E}$ inside the computational domain.

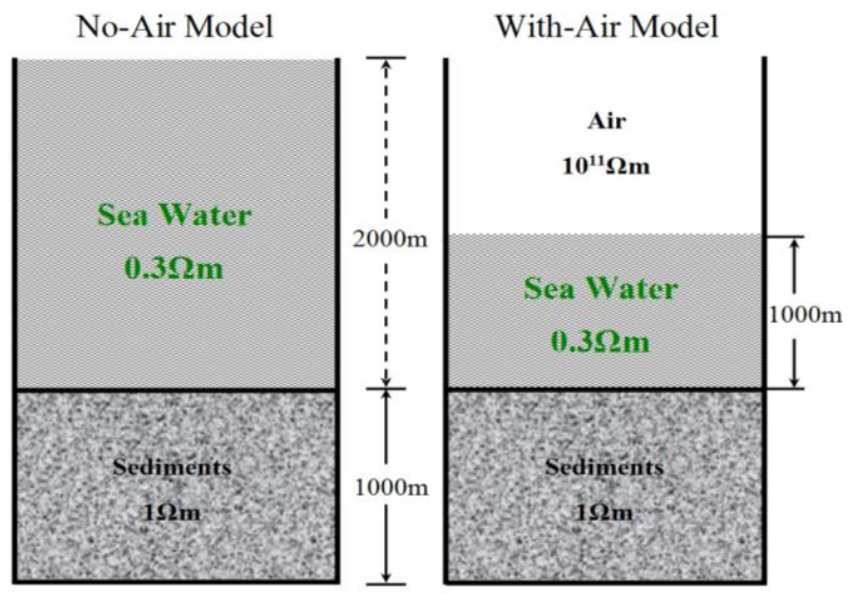

Fig. 3. 1D geo-electric model depicting No Air Model and With Air Model configurations.

Fig. 3 is a 1D geo-electric model depicting "No Air Model" and "With Air Model" configurations that were simulated to obtain the wave data. Note that the only difference between "No Air Model" and "With Air Model" is the changing of the sea water depth and replacing the space with air layer. We changed the sea water depth at interval of $100 \mathrm{~m}$ from $1000 \mathrm{~m}$ down to $100 \mathrm{~m}$. Table I present other physical values used for the simulation domains.

TABLE I

VALUES OF THE DOMAINS PHYSICAL PROPERTIES

\begin{tabular}{lllll}
\hline Domain & \multicolumn{1}{c}{$\begin{array}{c}\text { Relative } \\
\text { Permittivity } \\
\left(\varepsilon_{\mathbf{r}}\right)\end{array}$} & $\begin{array}{c}\text { Electric } \\
\text { Conductivity } \\
(\boldsymbol{\sigma})\end{array}$ & $\begin{array}{c}\text { Relative } \\
\text { Permeability } \\
\left(\boldsymbol{\mu}_{\mathbf{r}}\right)\end{array}$ \\
\hline Air & 1 & $1 \mathrm{e}^{-11}$ & 1 & \\
Sea Water & 80 & 3 & 1 & 1 \\
Sediment & 30 & 1.5 & & \\
\hline
\end{tabular}

The air waves data were computed by the method for removing the air wave effect as patented by [21] through the following steps:

1) Constructing a CSEM geometric model of the region having a top air layer, a middle sea water layer, and a bottom earth layer, with the model reflecting known 
bathymetry of the region and known conductivities of the air, seawater and earth;

2) Using the model to compute the electromagnetic field at all receiver locations for each source location;

3) Replacing the air layer in the model with sea water to create a no-air model;

4) Computing the fields for the same source-receiver geometries for the no-air model; and

5) Computing the air wave effect by subtracting the No-Air Model fields from the corresponding fields from the WithAir Model.

\section{Training of the Neural Network}

The two inputs parameters are offset distance (meters) and sea water depth (meters) and one output parameter is the computed air wave values. Data normalization is important due to the nature of log sigmoid training function [10]. Range of the data after normalization is [0 1$]$.

Selected data is given to the network during the training session with $\log$ sigmoid training function. Test data is not used in training session.

\section{RESULTS}

MCSEM Simulations was carried out along ten different sea water depths. The plot of the normalized values of air wave versus offsets in the ten sea water depths are presented in Fig. 4.

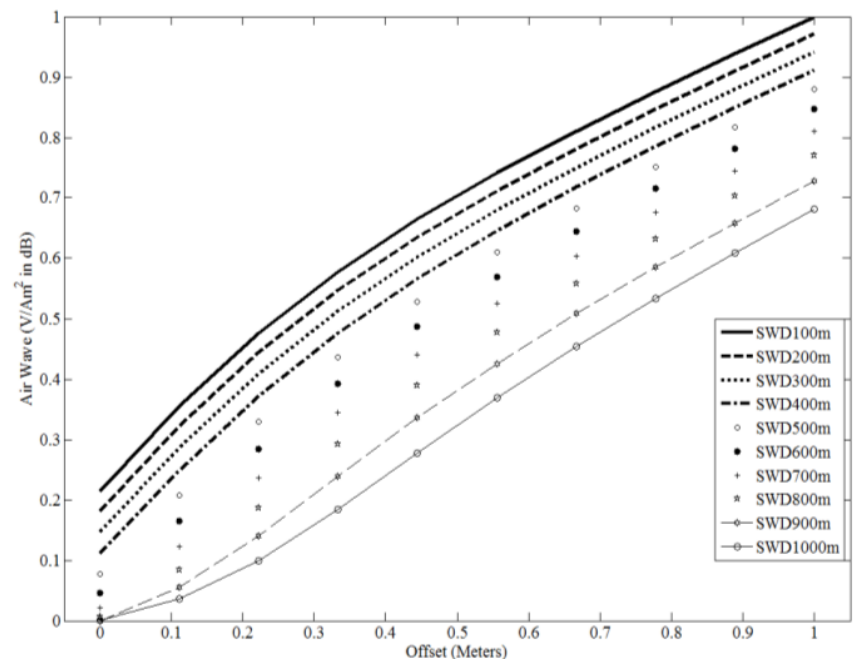

Fig. 4. Plot of the air waves values versus offsets for the sea water depths of $1000 \mathrm{~m}$ to $100 \mathrm{~m}$

The trend of the plot for the air wave values versus offsets shows that the air wave values are increasing as the offset increases. The pattern of the curves roughly suggest linearity in the relationship between the air waves values and the offset making it possible to the Multiple Linear Regression (MLR) model to the study data for performance comparison of the models.

In order to accomplish the Multiple Linear Regression (MLR) model for estimating the air wave. We express air wave value $(\mathrm{Y})$ as the response of the linear combination of the model terms $f\left(X_{i j}\right) \quad(i=j=1,2)$ representing the corresponding offset and sea water depth values at each of the observations, i.e. $\left(\mathrm{X}_{1}, \mathrm{X}_{2}, \mathrm{Y}_{1}\right), \ldots,\left(\mathrm{X}_{\mathrm{n}}, \mathrm{Y}_{\mathrm{n}}\right)$ as shown in equation (8).

$$
\underbrace{\left(\begin{array}{ccc}
f_{1}\left(x_{1}\right) \cdots f_{m}\left(x_{1}\right) \\
\vdots & \ddots & \vdots \\
f_{1}\left(x_{n}\right) & \cdots & f_{m}\left(x_{n}\right)
\end{array}\right)}_{X} \underbrace{\left(\begin{array}{c}
\alpha_{1} \\
\vdots \\
\alpha_{n}
\end{array}\right)}_{\alpha}+\underbrace{\left(\begin{array}{c}
\varepsilon_{1} \\
\vdots \\
\varepsilon_{n}
\end{array}\right)}_{\varepsilon}=\underbrace{\left(\begin{array}{c}
y_{1} \\
\vdots \\
y_{n}
\end{array}\right)}_{Y}
$$

Table II displays the parameters obtained for the multiple linear regression model.

\begin{tabular}{cc}
\multicolumn{2}{c}{ TABLE II } \\
MODEL PARAMETERS \\
\hline$\alpha_{1}$ & -0.3431 \\
$\alpha_{2}$ & 0.7705 \\
$\varepsilon$ & 0.2916 \\
Mean Square Error & 0.0011 \\
(MSE) & 0.9859 \\
R-Square & 0.9855 \\
\hline
\end{tabular}

The air wave data are first divided into training set (70\%), validation (15\%) and testing (15\%) for the ANN model. Training data were used to train the application; validation data were used to monitor the neural network performance during training and the test data were used to measure the performance of the trained application. Fig. 5 and 6 shows the neural network performance plot and the training, testing, validation and the overall neural network regression plot respectively.

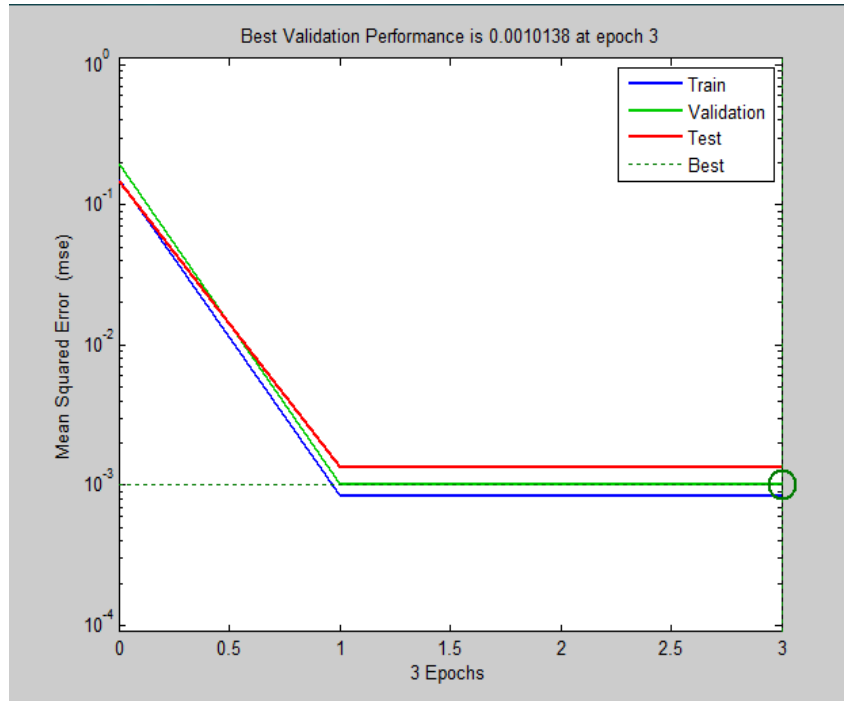

Fig. 5. Artificial Neural Network Performance Plot.

The neural network performance plot shown in Figure 5 indicated that the neural network achieved the best performance of 0.0010 after only 3 epoch. 


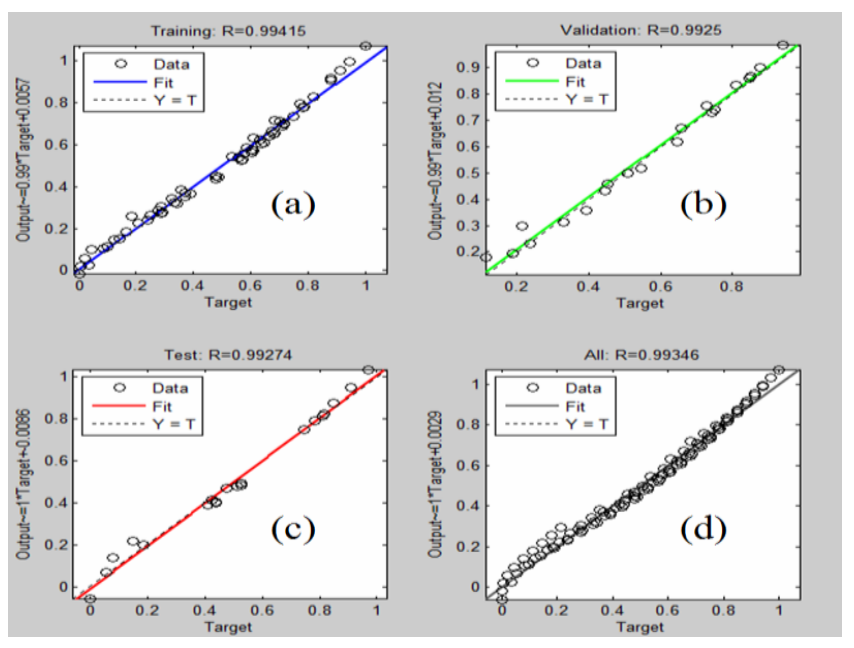

Fig. 6. (a) Training Regression Plot for the MLP. (b) Validation Regression Plot for the MLP. (c) Testing Regression Plot for the MLP. (d) Overall Regression Plot for the MLP.

Fig. 6(a) - (d) displays the networks training, validation, testing and the overall networks performance with 0.99415 , $0.9925,0.99274$ and 0.99346 as the coefficient of multiple determination respectively. The comparative results of MLP and MLR models are presented Table IV

TABLE IV

PERFORMANCE COMPARISON BETWEEN MLP AND MLR

\begin{tabular}{lcc}
\hline & $\begin{array}{c}\text { Mean Square Error } \\
\text { (MSE) }\end{array}$ & R-Square \\
\hline MLP Model & 0.00017 & 0.9935 \\
MLR Model & 0.0011 & 0.9859 \\
\hline
\end{tabular}

The results from the neural network indicate a lower error Mean Square Error of 0.00017 compared to using the conventional statistical method of multiple linear regression method with Mean Square Error of 0.0011. It is also observed that the overall coefficient of multiple determination for the MLP model is slightly better than that for the MLR model.

\section{CONCLUSION}

The purpose of this study was to investigate the applicability of Multi-Layer Perceptron neural networks in estimating air waves in MCSEM survey data. Simulations were carried out along ten different sea water depths and the air waves were computed by subtracting the response of the no-air background model from the response of the with-air background model. The research data was divided into training set $(70 \%)$, validation (15\%) and testing (15\%) for the MLP model. Coefficient of multiple determination and Mean Square Error (MSE) from the results of the MLP neural network and the conventional multiple linear regression model were used to compare the performance of the two models. Performance of the MLP model having better coefficient of multiple determination and smaller mean square error demonstrate it potential to estimate air waves in MCSEM data.

\section{ACKNOWLEDGMENT}

This research is carried out under the Fundamental and Research Grant Scheme. The authors would like to acknowledge Universiti Teknologi PETRONAS for giving the opportunity to carry out this research work.

\section{REFERENCES}

[1] L.O. Løseth, H.M. Pedersen, T. Schaug-Pettersen, S. Ellingsrud and T. Eidesmo, "A scaled experiment for the verification of the Sea Bed Logging method," Journal of Applied Geophysics 64 (2008) 47-55, December 2007.

[2] T. Eidesmo, S. Ellingsrud, L. M. MacGregor, S. Constable, M. C. Sinha, S. Johansen, F. N. Kong and H. Westerdahl, " Sea Bed Logging (SBL), a new method for remote and direct identification of hydrocarbon filled layers in deepwater areas, " First Break, March 2002, Vol. 20.3.

[3] E. M. SHOKIR, and El-M, "Prediction of the hydrocarbon saturation in low resistivity formation via artificial neural network" (SPE Technical Papers Series; 87001)

[4] S.E. Johansen and T.A. Wicklund, "Interpretation example of marine CSEM data" Electro-Magnetic Geo-Services as (emgs), Trondheim, EPX, Oslo, Norway THE LEADING EDGE MARCH (2007).

[5] S. Johansen, K. Brauti, S. Fanavoll, H. Amundsen. T. A. Wicklund, J. Danielson, P. T. Gabrielson, L. Lorentz, M. Frenkel, B. Dubois, O. Christensen, K. Elshaug and S. A. Karlsen, "How EM survey analysis validates current technology, processing and interpretation methodology," First Break, June 2008, Vol. 26.

[6] J. I. Nordskag and L. Amundsen, "Asymptotic airwave modeling for marine controlled-source electromagnetic surveying "GEOPHYSICS, VOL. 72, NO. 6 NOVEMBER-DECEMBER 2007; P. F249-F255

[7] A. D. Chave and C. S. Cox, "Theoretical numerical model study for offshore CESM exploration with a horizontal electric dipole source" Journal of Geophys. Res. 87, 5327-5338 (1982).

[8] W. L. Anderson, "Numerical integration of related Hankel transforms of order 0 and 1 by adaptive digital filtering," Geophysics, 44, (1979), pp.1287-1305.

[9] M. Brown and M. Poulton, "Locating buried objects for environmental site investigations using neural networks," Journal of Environmental and Engineering Geophysics 1, 179-188, (1996).

[10] M. McCormack, D. Zaucha and D. Dushek, "First break refraction picking and seismic data trace editing using neural networks" Geophysics 58, 67-78, (1993).

[11] A. Neyamadpour, S. Taib, W.A.T. Abdullah, "Inversion of 2D DC resistivity data for high resistivity contrast regions using artificial neural network" WSEAS International Conference on ENGINEERING MECHANICS, STRUCTURES, ENGINEERING GEOLOGY (EMESEG '08), Heraklion, Crete Island, Greece, July 22-24, 2008.

[12] M. Van der Baan and C. Jutten (2000). Neural Networks in Geophysical Applications: GEOPHYSICS, VOL. 65, NO. 4; P. 1032-047

[13] H. Demuth, M. Beale, M. Hagan, "Neural Network Toolbox ${ }^{\text {TM }}$ User's Guide "1992-2008 by The MathWorks, Inc.,3 Apple Hill Drive, Natick, MA: 01760-2098.

[14] A. Raiche, "A pattern recognition approach to geophysical inversion using neural networks," Geophysical Journal International 105, 629$648,(1992)$

[15] M. Poulton, K. Sternberg, and C. Glass, "Neural network pattern recognition of subsurface EM images," Journal of Applied Geophysics 29, 21-36, (1992).

[16] G. Roth and A. Tarantola, "Neural networks and inversion of seismic data," Journal of Geophysical Research 99, 6753-6768, (1994).

[17] G. El-Qady and K. Ushijima, "Inversion of DC resistivity data using neural networks," Geophysical Prospecting, 49, 417-430, (2001).

[18] U. K. Singh, V. K. Somvanshi, R. K. Tiwari, and S. B. Singh, "Inversion of DC resistivity data using neural network approach," In: Proceedings of the International Groundwater Conference, Dindigul, India, IGC-2002, pp. 57-64, (2002).

[19] M. Abdulkarim, Wan Fatimah Wan Ahmad, Afza, S., Radzuan R.," 2nd Annual International Conference on Advanced Topics in Artificial Intelligence (ATAI), ISSN: 2251-2179, doi: 10.5716/22512179 ATAI08,pp. 10-14, (2011). 
[20] M. Abdulkarim, Afza, S., Radzuan, R., Wan Fatimah Wan Ahmad, A. Agus,"Comparison on Performance of Radial Basis Function Neural Network and Discriminant Function in Classification of CSEM Data" Part 1, LNCS 7066, pp. 113-124, Springer-Verlag Berlin Heidelberg (2011).

[21] L. Xinyou, L. J. Srnka, and J. J. Carazzone, "Method for Removing Air Wave Effect from Offshore Frequency Domain Controlled-Source Electromagnetic Data,” U.S. Patent 7277 806, Oct. 2, 2007.

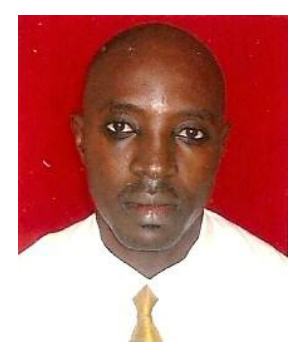

Muhammad Abdulkarim was born in Northern part of Nigeria in 70 's. He attended Nuru-Huda Primary School Zaria and Barewa College Zaria for primary and secondary education respectively. His obtained Bachelor's Degree in Statistics from University of Abuja Nigeria in 1998 and Master's Degree (M.Sc. Statistics) from Ahmadu Bello University Zaria, Nigeria in 2006.

$\mathrm{He}$ started his academic career as an academic staff of the department of Mathematics, Statistics and Computer Science, Faculty of Science, University of Abuja-Nigeria. He is a co-author of a book in Statistics first published in 2007- "A First Course In University Statistics". ISBN 978-125 140-9 Printed By Ahmadu Bello University Press Limited, P.M.B. 1094, Samaru, Zaria, Nigeria. He co-authored a book chapter for Lecture Notes in Computer Science- LNCS 7066, pp. 113-124, Springer-Verlag Berlin Heidelberg (2011). He has also published in both local and International scientific journals and conference articles including IEEE in 2011. Presently he belongs to the Novel Carbon Nano Fibres EM Transmitter in Conducting Medium research group Universiti Teknologi PETRONAS in Malaysia as a Doctoral research fellow/research officer. His current interest is in Data Mining with the application of Artificial Neural Network in modeling Control Source Electro-Magnetic (CSEM) data for deep and shallow water sea bed logging environment.

Abdulkarim is a registered member of the Nigerian Statistical Association (NSA). The prizes he won includes: Vice-Chancellor's Prize, Dean's Prize, Ashaka Cement Factory Prize, National Mathematical Centre Higher Education Scholarship for the Best Graduating Student University of AbujaNigeria (1998) and Best Student Paper Award at the 2nd Annual International Conference on Advanced Topics in Artificial Intelligence (ATAI) Singapore 2011. 